\title{
The Fundamental Role of Bacteria and Yeasts in AIDS Progression
}

\author{
Vladimir Zaja
}

Cancer Research Institute, Slovak Academy of Sciences, Vlarska 7, 83391 Bratislava, Slovakia

*Corresponding author: Vladimir Zajac, Cancer Research Institute, Slovak Academy of Sciences,Vlarska Street 7, 833 91,Bratislava, Slovakia, Tel: 02/ 5932 7318, 317; E-mail: vladimir.zajac@savba.sk

Received date: 28 April 2014; Accepted date: 19 June 2014; Published date: 24 June 2014

Copyright: (c) 2014 Zaja V. This is an open-access article distributed under the terms of the Creative Commons Attribution License, which permits unrestricted use, distribution, and reproduction in any medium, provided the original author and source are credited.

\begin{abstract}
Currently there is considerable evidence showing that the GIT and other mucosal tissue, and not the blood, are the main site of HIV infection and CD4 + T cell loss. Earlier the pathogenesis of HIV infection has mostly been centered on mucosal viral "target" cells. In this personal view we summarize recent findings related to the role of bacteria and yeasts in the etiopathology of AIDS. Data are presented showing detection of HIV-like sequences and HIV-like proteins in bacteria and yeasts of HIV positive patients from the USA, Slovakia, Kenya and Kambodia. This pioneer view of AIDS etiopathology suggests that the aforementioned microbes bearing HIV genetic information would play an important, if not a key role, in the immunodeficiency process.
\end{abstract}

Keywords: Bacteria; Yeasts; AIDS

\section{Introduction}

A large number of diseases have appeared during the past half century from so far expressly unexplained reasons. Among one of the most feared representatives is the acquired immune deficiency syndrome (AIDS). AIDS emerged suddenly, unexpectedly and in the course of less than three decades became one of the leading diseases in the world. Despite unquestionable success in diagnostics and therapy of AIDS, there are many unanswered questions. Yet without giving answers to these questions, a more successful treatment of patients can not be expected. A strong argument for this claim is the fact that it has not been possible to stop the global spread of AIDS, especially in Africa and Asia.

A majority of scientists and clinicians have accepted the data leading to the conclusion that HIV alone is the etiologic agent responsible for this disease and that it was transferred to humans from monkeys/chimpanzees in Africa through random contacts 35 to 50 years ago [1-4]. Some experts substantiated African AIDS as a direct result of a WHO smallpox eradication program conducted in the 1970 $[5,6]$. The smallpox vaccine allegedly awakened a "dormant" HIV infection in the black population. One of the most frequently published ideas is that the primate/simian virus resulted in the virus laboratory. All these claims, however, are not sufficiently substantiated. On the other side, specialists as Duesberg, Rasnick, Crowe and others form a strong opposition to the HIV=AIDS dogma [7]. Many opponents present a different dogma - HIV does not exist, or if so, it is a harmless element which is not responsible for AIDS. Like proponents of the HIV=AIDS dogma, they have many strong arguments for their proposition: a) many patients diagnosed with AIDS were HIV negative; b) there is no evidence of retrovirus transmission between different species in nature. Is HIV the only exception in nature?

The current complex situation in AIDS research and therapy is challenging for us to fight against AIDS in a more complex manner and to overcome all taboos and dogmas surrounding this disease.
Firstly, it is necessary to respect other potential factors, not only HIV, which may be involved in this disease.

\section{AIDS and GIT}

Mattapallil, Veazey, Li and others showed that the major focus of memory $\mathrm{CD} 4+\mathrm{T}$ cell destruction by the simian immunodeficiency virus (SIV) is in mucosal and peripheral tissues, where most $\mathrm{T}$ cells expressing CD4 and CCR5 with a "memory" phenotype reside [8-11]. During acute simian immunodeficiency virus infection, antiretroviral therapy prior to acute viral replication preserves CD4 $\mathrm{T}$ cells in the periphery but not in the rectal mucosa $[12,13]$. The loss of $\mathrm{CD} 4^{+} \mathrm{T}$ cells in the intestine occurs coincidently with productive infection of large numbers of mononuclear cells at this site. Peak SIV replication in resting memory $\mathrm{CD} 4^{+} \mathrm{T}$ cells depletes the gut lamina propria of $\mathrm{CD} 4^{+}$ $\mathrm{T}$ cells [14]. These recent findings support the idea that the mucosal and intestine immune system is the major site of viral replication, persistence and $\mathrm{CD}^{+} \mathrm{T}$ cell loss in HIV-1 infected persons [15-18]. Consequently, gastrointestinal disease, a major complication of HIV/SIV infection, can facilitate translocation of lumenal bacterial products causing localized/systemic immune activation leading to AIDS progression [19]. There has been encouraging recent success in the development of safe and effective topical microbicides to prevent vaginal or rectal HIV-1 transmission, based on the use of antiretroviral drugs. However, much work remains to be accomplished before a microbicide becomes a standard element of preventive science strategies. Animal models should continue to play an important role in pre-clinical testing and pharmacokitetic efficacy testing, with emphasis on safety [20]. There is evidence of an increased pathogenic footprint in the lingual microbiome of untreated HIV infected patients [21]. Monkeys infected with simian immunodeficiency virus have a higher diversity of gut viruses, pointing to a possible role of the virome in SIV pathogenesis [22]. The HIV was detected in bowel epithelium from patients with gastrointestinal symptoms and in the bowel crypt cells and lamina propria [23,24]. The fact that these cells are in close vicinity to intestinal bacteria, gave rise to the idea that bacteria may also be involved in AIDS pathogenesis. 
Some groundbreaking findings made by Livingston, Broxmeyer and Cantwell pointed out that there was a very close link between bacteria and cancer as well as AIDS [25-28]. This interest in investigating bacteria and mycoplasma in this disease was also supported by Montagnier's finding, confirmed by Shyh-Ching Lo, that mycoplasma is a very important "co-factor" which accelerates the progression of HIV infection in AIDS patients [29,30]. There are new studies on the role of bacteria and of antibiotics in AIDS defining diseases [31]. It demonstrates clearly that bacteria belonging to the normal flora in the oral cavities, in the gut and the vagina can induce transcription of silenced genes, including HIV-1 provirus. These findings go along with new studies on the role of bacterial translocation in the gut as central driver of AIDS-pathogenesis.

\section{Our approach in the study of bacteria and yeasts of HIV positive patients}

The above mentioned findings and examinations determined our research orientation to intestinal bacteria and yeasts. In the effort to find an answer to this basic question, an original, untraditional approach was used based on the idea that bacteria and yeasts should be among the possible vectors of HIV transmission. The idea considered the aforementioned hypothesis and involved our long-term laboratory and field experience with bovine leukemia virus (BLV). This resulted in the detection of BLV sequences in the bacteria of leukemic cows [data not published]. The first, most important step in the experimental realization of the given idea was to test bacteria isolated from the gastrointestinal tract and blood of AIDS patients and healthy persons for the presence of HIV-1 sequences. So far no evidence of such sequences was found in any kind of bacteria. The main reason for this fact is that effort in this field has been oriented only on proving the origin of retroviruses from eukaryotes.

Based on this idea, bacteria were isolated from the gastrointestinal tract of 54 Slovak and American AIDS patients. The study protocol of Slovak patients was reviewed and approved by the Scientific Board and Ethical Committee of the Hospital of Medical Faculty, Comenius University, Bratislava. Bacteria and yeasts isolated from the respiratory tract of 72 Kambodian and Kenyan HIV positive children were tested for the presence of HIV-1 sequences by colony and dot blot hybridization [32-35]. Positive hybridization for $80-90 \%$ was achieved in the cohort of American and Slovak AIDS patients by using PCR product probes from all main parts of the HIV-1 genome: gag, pol and env prepared on the templates: a) of plasmid pBH10 (GenBank accession number M15654) bearing HIV-1 provirus; b) DNA isolated from lymphocytes of an AIDS patient. On the other hand, a positive signal for $35 \%$ respectively $38 \%$ was detected in respiratory bacteria and yeasts of Cambodian and Kenyan HIV positive children. The PCR products synthesized on the template of the analyzed bacterial and yeast DNA using primers from gag, pol and env genes were sequenced and at least $90 \%$ homology to HIV-1 was detected.

The possible expression of bacterial HIV-like protein was tested by MABs against HIV-1 p17, p24, p55, gp41 and gp120. By using monoclonal antibodies against HIV-1 proteins p17 and p55, the protein with the molecular weight of $55 \mathrm{kDa}$ was detected in samples of all cohorts tested. Its molecular weight is comparable to the gagencoded Pr55Gag precursor. Application of MAbs against p24 disclosed the protein of $55 \mathrm{kDa}$ in Cambodian and Kenyan samples, but no proteins were detected in bacterial extracts from the American and Slovak AIDS patients tested. Using MAb against HIV-1 specific protein gp41, the protein of $41 \mathrm{kDa}$ was identified in $30-35 \%$ of samples from children patients from Kenya and Cambodia and in $75 \%$ of samples from American and Slovak patients. The use of MAbs against gp120 detected the protein of about $85-95 \mathrm{kDa}$ only in Candida species protein extracts from Cambodian and Kenyan HIV positive children. The results indicate that there are specific differences between bacterial proteins of Slovak and American HIV positive patients on the one side and Cambodian and Kenyan on the other. These differences may suggest diverse bacterial evolution in various geographical areas.

We performed several experiments to analyze the role of bacteria bearing HIV sequences in the AIDS process. Analogous to the finding of Swidzinski [36] that bacteria isolated from biopsies of polyps, adenomas, and carcinomas are able to internalize epithelial cells [37], we tested bacteria of patients with colorectal problems by gentamicin protection assay (GPA) [38]. According to this approach, we used bacteria isolated from AIDS patients for testing their ability to internalize HL-60 cells. We found that these bacteria had a strong, more than 10-15 times higher capability of internalizing HL-60 cells as compared to bacteria of patients with colorectal problems (data prepared for publication). Consequently, it was proven that bacteria of the intestinal tract of AIDS patients were able to internalize and lyse normal human lymphocytes with a high efficiency. What is the fate of bacteria after internalization? We demonstrated that about $65-75 \%$ of the bacteria of the AIDS patients tested were competent to lyse HL-60 and host lymphocytes. As shown by the GPA test, the other part of intracellular bacteria survived in the host cells for further 7-10 days and post hoc the GPA test was negative. It can be assumed that in nature some pathogenic bacteria which penetrated into the blood system may infect or lyse lymphatic cells.

For analysis of the role of bacteria in immunodeficiency, reduction of their amount in the intestinal tract of HIV/AIDS patients was performed by oral administration of probiotic bacteria Escherichia coli strain Nissle 1917. After three months of probiotics treatment the viral load decreased or remained on the detection limit $(<400 \mathrm{c} / \mathrm{ml})$ at $55.5 \%$ in the patients tested. The viral load of all patients in the study completely trimmed down by about $67 \%$ (data prepared for publication).

\section{Hypothetical role of bacteria and yeasts in AIDS}

According to these results, some bacteria and yeasts of the human gastrointestinal and respiratory tract are carrying HIV sequences in chromosomal and mainly extra-chromosomal form. These intestinal bacteria were classified as Escherichia coli, Proteus mirabilis, Citrobacter freundii, Staphylococcus sp., and Enterobacter aerogenes. Bacteria isolated from the respiratory tract of HIV positive children are mostly Staphylococcus aureus (MRSA), Candida albicans, Klebsiella pneumoniae and Proteus mirabilis. These bacteria and yeasts are generally resistant, some of them multiresistant, to antibiotics. The resistance to ATBs is largely coded by plasmids and transposons, integrons and gen-casettes in which also genes for adhesion to intestinal cells may be localized [39-41]. After adhesion, bacteria equipped in this manner are able to penetrate via colon epithelial cells into the lymphatic system, and consequently, into the bloodstream [42]. There are many different bacterial strains in the intestinal tract which are able to internalize human cells with affinity to various organs. As detected, some of them carrying HIV sequences have a high affinity to human lymphocytes. When these bacteria enter into human lymphocytes, HIV sequences, like on a tray, pass into lymphocytes. The following events are dependent on the nature of the 
bacteria. We suppose that there are at least two possibilities: a) bacteria lyse the host lymphocytes and consequently HIV sequences in chromosomal or extra-chromosomal form are released into the bloodstream and may directly infect lymphocytes, macrophages or other cells of the lymphoproliferative system; b) bacteria are internalized in lymphocytes or macrophages and consequently HIV sequences may be integrated into the lymphocyte's or macrophage's DNA in the abovementioned form. In the case of an infection of CD4 + memory cells, HIV sequences may remain in this state for months or even years, and may be transferred to newly synthesized cells.

Based on these findings, it is assumed that in the case of AIDS two biological components - HIV genetic information and its bacterial host - play an important role. The form and presence of HIV-like sequences are questionable and as mentioned before, it is very likely that bacteria not bearing the complete retroviral form, the LTR sequences were not detected. The explanation of the presence of HIV sequences in commensally ingested bacteria of the patients is as follows: 1) intestinal bacteria were infected by HIV released from degraded human cells, in particular by macrophages and lymphocytes; 2) intestinal bacteria of AIDS patients are a natural host of HIV sequences.

\section{Evolution of human microflora in the context with AIDS}

Following this consideration, we assume that the presence of HIV in the human population has the same genesis: we inherited this HIV genetic information from our ancestors since the beginning of humankind and subsequently it has been translated from generation to generation. But there is a very serious objection - if HIV information was in our bacteria from our beginning, why did it emerge just about 25 years ago? Was it hidden without any implication all the time, for many thousands of years, in our bodies?

To answer this question, we should return to the ancient history of mankind. In the past, large epidemics often occurred when there were new patterns of communication and transport between populated areas and/or new patterns of settlement. According to historians, the first registered large epidemic occurred in Athens during the Peloponnesian War in 430 BCE. In the middle of the sixth century AD (542), there was a big outbreak of bubonic plague (Justinianus) in the Mediterranean countries, where 40 to $50 \%$ of the population died. The biggest cataclysm of bubonic plague epidemic started in 1346 in Europe and subsequently spread to Asia, with the population eventually decimated by 50 to $60 \%$. At least 60 million people died in China alone. This plague continued up to the seventeenth and partially to the eighteenth century. In the sixteenth century, after Europeans reached America, new devastating epidemics started among the native peoples resulting in a $90 \%$ population loss among American Indians within 120 years.

Who were particularly the victims of these plagues? Especially people who were weak, malnourished, sick, so people with depleted immune systems. As discussed above, bacteria carrying the rich extra chromosomal genetic information as plasmids, phages, transposons, retrotransposons, containing various genetic information, HIV including, are mostly pathogenic for the host and after penetration into the organism they continually attack the immune system. This attack depends on the amount of these microbes which penetrate into the blood. The immune system of people with low amounts of these bacteria was stronger and their carriers had a chance to overwhelm any plague. One of the most important results of the set of plagues that occurred in the history of humankind, mainly in Europe, North
Africa, North America and partially in Asia, was natural selection, resulting in "sanitation" of the human population. Hand in hand in this tremendous evolution process was the selection of people with low level of bacteria carrying pathogenic, mainly extra chromosomal genetic information, able to penetrate into the human body and attack the immune system. The result of this complex evolutional proceeding, which finished towards the end of the nineteenth century, was establishment of a balance between non-pathogenic and pathogenic ("good" and "bad") microbes in the microflora of surviving individuals. In short, the result of this long process was the selection of individuals with a very limited number of bacteria carrying the HIV sequences and those carrying CCR-5 receptor deficiency on white blood cells.

This stability, acquired over many centuries, was interrupted in the middle of the twentieth century, in the time of the antibiotics era. It is generally accepted that due to ATB, practically all primary bacterial pathogens were liquidated over two-three decades. The success of antibiotics in elimination of many diseases induced by microbes was so expressive that in the mid-1950s the US Surgeon General Steward effusively proclaimed the era of bacterial diseases finished. This trend of ATB glorification was spread very quickly from the USA to Europe and microbiology found itself at the scientific periphery. In 1969, only a few people heard the voice of the English scientist J. A. Reaburn who said that antibiotics would bring us unforeseen vicious tricks in the future. ATB treatment results in reduction of not only pathogens but also of symbiotic or otherwise beneficial microflora. For survival, bacteria need to acquire the ability to escape from ATB pressure by: a) induction of ATB resistance; b) penetration into mammalian cells, where they are able to survive for a rather long period of time; c) by changing their own face pleomorphism - creation of a cell-wall-deficient (CWD) form.

Bacteria which obtained resistance to ATB are different from their ancestors. They achieved new properties in balancing the new condition, without respect of human hosts. Unlimited application of ATBs, drugs, pharmaceuticals on the one hand and anal sexual intercourse on the other, triggered changes in the equilibrium of the human intestinal microflora, which was constituted during many centuries. A mass-scale usage of inhalants (e.g. popper) in the USA during the 1970s and drugs in the 1980s, especially in homosexual communities combined with unlimited intercourse (homo and anal sex), was the last heavy shot into the balance of intestinal microflora of many people. In addition, the situation in the USA became complicated because of African Americans who were not involved in the mentioned long-term selection "sanitary" process as were Americans who emigrated from Europe.

The wide range of HIV-positivity in Africa is explained by the longterm survival of Africans in isolated communities. There was no selection "sanitary" process (intensively occurring in Europe) causing limitation of potentially pathogenic bacteria carrying extrachromosomally localized viral sequences, genes for resistance, adhesion and penetration into human cells. The presence of HIV sequences in bacteria of Africans is so widespread that it can not be used as "gold" standard. In light of our preliminary findings we suppose that the association of AIDS and TB in Africa is a result of transfer of HIV bacterial genetic information via plasmids, transposons, retrotransposons or other integrons into Mycobacterium tuberculosis.

The presence of HIV sequences in respiratory bacteria and yeast of Cambodian and Kenyan HIV-positive children shows that these 
microbes are present not only in the gastrointestinal tract but in the whole body. Because of their broad resistance to antibiotics and "resistance" to nucleoside analogue drugs (AZT), their elimination in GIT is practically impossible by various combinations of ART. According to our results, GIT bacteria may represent a very important HIV reservoir. The continual application of ART, including antibiotics, resulted in total reduction of sensitive bacteria and amplification of resistant ones. Toxicity of AZT plays a very important negative role in this process. The result of this spiral process is the presence of only resistant bacteria, many of them with HIV sequences. These microorganisms penetrate from the GIT into the body of patients, reduce the number of $\mathrm{T}$-cells and ultimately induce immunodeficiency.

\section{Conclusion}

The obtained results suggest that the reduction of $\mathrm{CD} 4^{+}$cells is due to the cytotoxic effect of special bacterial strains bearing HIV sequences. These, mostly multi-resistant pathogenic bacteria including those containing HIV sequences - moved from a minority to the majority, overcame the intestinal barrier, began to continuously attack the immune system, decreasing the $\mathrm{CD} 4^{+}$cell count. When this falls below $200 / \mu \mathrm{l}$, the immune system becomes dysfunctional and the syndrome of immunodeficiency can start [43]. In the conditions of immunodeficiency, bacterial infections are taking over in the whole human body. Germs internalized in human cells can be released from the host cells and induce various infections - tuberculosis, pneumocystosis, giardiasis, salmonellosis, cytomegalovirus and herpes virus infections, toxoplasmosis, and others. After degradation of the host cell, genetic information released from bacteria with HIV sequences may interact with human DNA. These elements flow into the blood stream, and because of their high affinity they bind to lymphocyte CD4 receptors and consequently penetrate into them. The integration of HIV genetic information into the DNA of $\mathrm{CD}^{+}$cells results in their lysis and makes them non-functional. The presented hypothesis answers many until now unanswered questions: origin of HIV, large scale HIV positivity in Africa, connection of AIDS with TB in Africa, absence of the "gold standard" in Africa, presence of HIV reservoirs after antiretroviral therapy, atypical course of disease in comparison with other retroviral infections, rarity of complete viral particles detection in the material from AIDS patients, yet detection of HIV sequences and HIV proteins (antigens) herein, high AZT toxicity, and several others $[44,45]$.

Our findings indicate that the disease is a consequence of changes in the global process of human intestinal microflora, refusing thereby indirectly the argument that HIV was created in the laboratory and AIDS is actually one of the biological weapons. The hypothesis expressly contradicts the dogma, presented in peer-reviewed journals, justifying the AIDS pandemic (a worldwide presence in 35 million HIV positives!) by retrovirus transmission (HIV) in Africa from monkeys to humans in the past 35 to 50 years as a result of accidental contacts. And that is good news for Africa.

The confirmation of our hypothesis may open new perspectives in diagnostics and AIDS therapy, aimed at recovering the host microorganism relationships and based on elimination of bacteria and yeasts bearing HIV genetic information, an approach that should not be very burdensome for patients. Our results are quite preliminary and they can be considered only as generating hypotheses. Our study is a pilot project and still more research is warranted.

\section{Acknowledgments}

The authors' work was supported by a grant from the Slovak Research and Development Agency (APVV-06-46-11). This publication is also the result of the project implementation: SF ITMS project code: 26240220058 supported by the Research \& Development Operational Programme funded by the ERDF.

\section{References}

1. Gallo RC, Wong-Staal F (1985) A human T-lymphotropic retrovirus (HTLV-III) as a the cause of the acquired immunodeficiency syndrome. Ann Intern Med 103: 679-689.

2. Sharp PM, Bailes E, Chaudhuri RR, Rodenburg CM, Santiago MO, et al. (2001) The origins of acquired immune deficiency syndrome viruses: where and when? Philos Trans R Soc Lond B Biol Sci 356: 867-876.

3. Zhu T1, Korber BT, Nahmias AJ, Hooper E, Sharp PM, et al. (1998) An African HIV-1 sequence from 1959 and implications for the origin of the epidemic. Nature 391: 594-597.

4. Apetrei C, Marx PA (2005) African lentiviruses related to HIV. J Neurovirol 11 Suppl 1:33-49.

5. Belshe RB, Bolognesi DP, Clements ML, Corey L, Dolin R, et al. (1994) HIV infection in vaccinated volunteers. JAMA 272: 431.

6. Bartlett J, del Rio C, DeMaria A Jr, Sepkowitz KA (2003) Smallpox vaccination and the HIV-infected patient: a roundtable. AIDS Clin Care 15: 61-63.

7. Duesberg PH (1987) Retroviruses as carcinogens and pathogens: expectations and reality. Cancer Res 47: 1199-1220.

8. Ling B, Veazey RS, Hart M, Lackner AA, Kuroda M, et al. (2007) Early restoration of mucosal CD4 memory CCR5 T cells in the gut of SIVinfected rhesus predicts long term non-progression. AIDS 21: 2377-2385.

9. Mattapallil JJ, Douek DC, Hill B, Nishimura Y, Martin M, et al. (2005) Massive infection and loss of memory CD4+ T cells in multiple tissues during acute SIV infection. Nature 434: 1093-1097.

10. Moore AC, Bixler SL, Lewis MG, Verthelyi D, Mattapallil JJ (2012) Mucosal and peripheral Lin- HLA-DR+ CD11c/123- CD13+ CD14mononuclear cells are preferentially infected during acute simian immunodeficiency virus infection. J Virol 86: 1069-1078.

11. Kader M, Bixler S, Roederer M, Veazey R, Mattapallil JJ (2009) CD4 T cell subsets in the mucosa are CD28+Ki-67-HLA-DR-CD69+ but show differential infection based on alpha4beta7 receptor expression during acute SIV infection. J Med Primatol 38 Suppl 1: 24-31.

12. Wilson DP, Mattapallil JJ, Lay MD, Zhang L, Roederer M, et al. (2007) Estimating the infectivity of CCR5-tropic simian immunodeficiency virus SIV(mac251) in the gut. J Virol 81: 8025-8029.

13. Moore AC, Bixler SL, Lewis MG, Verthelyi D, Mattapallil JJ (2012) Mucosal and peripheral Lin- HLA-DR+ CD11c/123- CD13+ CD14mononuclear cells are preferentially infected during acute simian immunodeficiency virus infection. Virol 86: 1069-1078.

14. Li Q1, Duan L, Estes JD, Ma ZM, Rourke T, et al. (2005) Peak SIV replication in resting memory $\mathrm{CD} 4+\mathrm{T}$ cells depletes gut lamina propria CD4+ T cells. Nature 434: 1148-1152.

15. Veazey RS, DeMaria M, Chalifoux LV, Shvetz DE, Pauley DR, et al. (1998) Gastrointestinal tract as a major site of CD4+ T cell depletion and viral replication in SIV infection. Science 280: 427-431.

16. Dandekar S (2007) Pathogenesis of HIV in the gastrointestinal tract. Curr HIV/AIDS Rep 4: 10-15.

17. Guadalupe M, Sankaran S, George MD, Reay E, Verhoeven D, et al. (2006) Viral suppression and immune restoration in the gastrointestinal mucosa of human immunodeficiency virus type 1-infected patients initiating therapy during primary or chronic infection. J Virol 80: 8236-8247.

18. Mehandru S, Dandekar S (2008) Role of the gastrointestinal tract in establishing infection in primates and humans. Curr Opin HIV AIDS 3: 22-27. 
Citation: Zaja V (2014) The Fundamental Role of Bacteria and Yeasts in AIDS Progression. J Vaccines Vaccin 5: 238. doi: $10.4172 / 2157-7560.1000238$

Page 5 of 5

19. Mehandru S1, Dandekar S (2008) Role of the gastrointestinal tract in establishing infection in primates and humans. Curr Opin HIV AIDS 3: 22-27.

20. Mohan M, Kaushal D, Aye PP, Alvarez X, Veazey RS, et al. (2012) Focused examination of the intestinal lamina propria yields greater molecular insight into mechanisms underlying SIV induced immune dysfunction. PLoS One 7: e34561.

21. Veazey RS, Shattock RJ, Klasse PJ, Moore JP (2012) Animal models for microbicide studies. Curr HIV Res 10: 79-87.

22. Dang AT, Cotton S, Sankaran-Walters S, Li CS, Lee CY, et al. (2012) Evidence of an increased pathogenic footprint in the lingual microbiome of untreated HIV infected patients. BMC Microbiol 12: 153.

23. Handley SA, Thackray LB, Zhao G, Presti R, Miller AD, et al. (2012) Pathogenic simian immunodeficiency virus infection is associated with expansion of the enteric virome. Cell 151: 253-266.

24. Nelson JA, Wiley CA, Reynolds-Kohler C, Reese CE, Margaretten W, et al. (1988) Human immunodeficiency virus detected in bowel epithelium from patients with gastrointestinal symptoms. Lancet 1: 259-262.

25. HIV detected in bowel epithelium from patients with gastrointestinal symptoms. Lancet 6: 259-62.

26. Veazey RS, Lackner AA (2005) HIV swiftly guts the immune system. Nat Med 11: 469-470.

27. Livingston V (1972) Cancer: a new Breakthrough. Los Angeles: Nash Publishing Company.

28. Cantwell Jr AR (1993) Necroscopic findings of variably acid-fast bacteria in a fatal case of acquired immunodeficience syndrome and Kaposi's sarcoma. Growth 47: 129-34.

29. Cantwell AR Jr (1983) Kaposi's sarcoma and variably acid-fast bacteria in vivo in two homosexual men. Cutis 32: 58-61, 63-4, 68

30. Broxmeyer L, Cantwell A (2008) AIDS: "it's the bacteria, stupid!". Med Hypotheses 71: 741-748.

31. Montagnier L, Vaincre le SIDA(1986) Entretiens avec Pierre Bourget. Paris, Editations Cana.

32. Lo SC, Tsai S, Benish JR, Shih JW, Wear DJ, et al. (1991) Enhancement of HIV-1 cytocidal effects in CD4+ lymphocytes by the AIDS-associated mycoplasma. Science 251: 1074-1076.

33. Imai K, Yamada K, Tamura M, Ochiai K, Okamoto T (2012) Reactivation of latent HIV-1 by a wide variety of butyric acid-producing bacteria. Cell Mol Life Sci 69: 2583-2592.
34. V Zajac V, Kovac M, Ciernikova S, Mego M, Rauko P, et al. (2005) Detection of HIV sequences in colon bacteria of AIDS positive patients. Clin. Microbiol Infec 11: 53.

35. Zajac V, Mego M, Martinický D, Stevurková V, Cierniková S, et al. (2006) Testing of bacteria isolated from HIV/AIDS patients in experimental models. Neuro Endocrinol Lett 27 Suppl 2: 61-64.

36. Zajac V, Stevurkova V, Matelova L, Ujhazy E (2007) Detection of HIV-1 sequences in intestinal bacteria of HIV/AIDS patients. Neuro Endocrinol Lett 28: 591-595.

37. Zajac V, Adamcikova Z, Holec V, Hainova K, Stevurkova V, Matelova L et al. (2011) Microbes, viruses and parasites in AIDS process“. Printed in INTECH : 375-390.

38. Swidsinski A1, Khilkin M, Kerjaschki D, Schreiber S, Ortner M, et al. (1998) Association between intraepithelial Escherichia coli and colorectal cancer. Gastroenterology 115: 281-286.

39. Martin HM, Campbell BJ, Hart CA, Mpofu C, Nayar M, et al. (2004) Enhanced Escherichia coli adherence and invasion in Crohn's disease and colon cancer. Gastroenterology 127: 80-93.

40. Mego M, Májek J, Konceková R, Ebringer L, Cierniková S, et al. (2005) Intramucosal bacteria in colon cancer and their elimination by probiotic strain Enterococcus faecium M-74 with organic selenium. Folia Microbiol (Praha) 50: 443-447.

41. Beachey EH (1981) Bacterial adherence: adhesin-receptor interactions mediating the attachment of bacteria to mucosal surface. J Infect Dis 143: 325-345.

42. Cohen PS, Laux DC (1995) Bacterial adhesion to and penetration of intestinal mucus in vitro. Methods Enzymol 253: 309-314.

43. Klemm P, Schembri MA (2000) Bacterial adhesins: function and structure. Int J Med Microbiol 290: 27-35.

44. Benjamin P, Federman M, Wanke CA (1995) Characterization of an invasive phenotype associated with enteroaggregative Escherichia coli. Infect Immun 63: 3417-3421.

45. Dandekar S, George MD, Bäumler AJ (2010) Th17 cells, HIV and the gut mucosal barrier. Curr Opin HIV AIDS 5: 173-178. 